The tube is constructed ${ }^{1}$ of the best quality of red rubber. The wall is $2 \mathrm{~mm}$. thick and the lumen has a diameter of 9 $\mathrm{mm}$. The tube is made in two sections, distal and proximal, connected by a thin, but strong, aluminum midpiece.

1. The distal segment of the tube is $90 \mathrm{~cm}$. long. It has a distal opening of $1 \mathrm{~cm}$. diameter. Beginning $1 \mathrm{~cm}$. from this tip is a lateral fenestrum (Fig. 1) of ellipsoid form, $2 \mathrm{~cm}$. long and $1 \mathrm{~cm}$. wide. On the opposite lateral surface to this is a second similar lateral fenestrum, which begins $3 \mathrm{~cm}$. from the tip of the tube. The fenestrum is placed at this point, not only to permit free siphonage of gastric contents, but also to facilitate the introduction of the tube. Its location, $3 \mathrm{~cm}$. from the tip of the tube, is the average distance in different

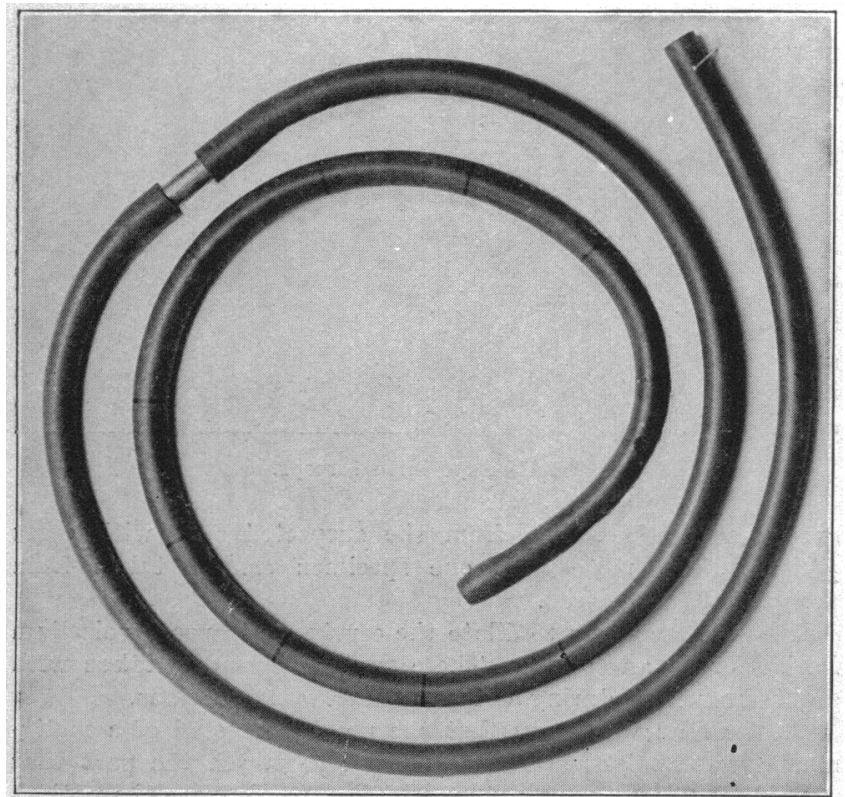

Fig. 2.-Full view of tube, showing segments, markings and fig. 2.-Full view or tube, showing segments, markings and fenestra on distal segmen
separated to show this).

individuals from the pharyngeal bend of the tongue to the introitus esophagi. When the tip of the tube enters the pharynx, with the second lateral fenestrum toward the tongue, the subject's swallowing motions promptly bend the tube at this fenestrum and the tip glides readily into the esophagus. Using a tube with a distal end of this type, we have not entered the larynx more than a dozen times in our last five thousand cases. Eight centimeters from the tip of the tube are placed three round fenestra, of a diameter of $2 \mathrm{~mm}$. They pierce the tube at the same level. This distal segment of the tube, beginning $10 \mathrm{~cm}$. from its tip, is marked off by encircling black lines (Fig. 2), every $5 \mathrm{~cm}$. for a distance of $55 \mathrm{~cm}$. from the distal end. These markings permit of fairly accurate location of obstructions in the esophagus. The tube, in such instances, acts as a hollow sound through which the contents of esophageal sacculations and the like may be readily secured.

2. The connecting aluminum midpiece is $5 \mathrm{~cm}$. long, with a wall $1 \mathrm{~mm}$. thick and a lumen of $1 \mathrm{~cm}$. diameter. It is slightly roughened and fits snugly into the rubber parts. It is non-rusting.

3. The proximal end of the tube is $60 \mathrm{~cm}$. long. It may be replaced, when necessary, by an aspiration bulb which fits onto the metal midpiece.

The advantages of the type of tube described appear to be:

1. These tubes are durable; they may be boiled for months and still retain their form.

2. The lumen is large enough to permit free expression or aspiration of retention contents after the administration of a motor test-meal.

3. The distal fenestra are so placed as to permit the easy passage of the tube and the rapid siphonage or aspiration of

1. These tubes are Goodyear make. gastric contents. Free lavage is readily carried on, either for the purpose of determining retention (as in hour-glass stomach) or for therapeutic effect.

4. The tube acts as a safe and convenient esophageal sound.

5. The aluminum midpiece replaces easily broken glass connections. It enables one rapidly to convert the straight siphon or lavage tube into one of bulbed type for the purpose of inflating the stomach with air and when expression of gastric contents proves difficult.

122 South Michigan Avenue.

\section{A SIMPLE DEVICE FOR PROTECTION AGAINST INFECTION IN NOSE' AND THROAT EXAMINATIONS}

\section{J. F. Croveir and C. A. Clapp, M.D., Baltimore}

Most devices which are used by the physician to lessen the danger of infection during examinations of the nose or throat are either so uneomfortable or so inconvenient that they are infrequently used. A very simple device which we have used with great satisfaction for several years consists of a pair of Jumbo-sized steel or aluminum spectacles with either plano or one's own correction for the lenses. To the nose-piece is fastened a piece of aluminum sheet which is bent to a V shape to allow room for the nose and extends downward to cover the mouth.

It serves to protect the eyes, nose and mouth from any spray and its great convenience in putting on or off, together

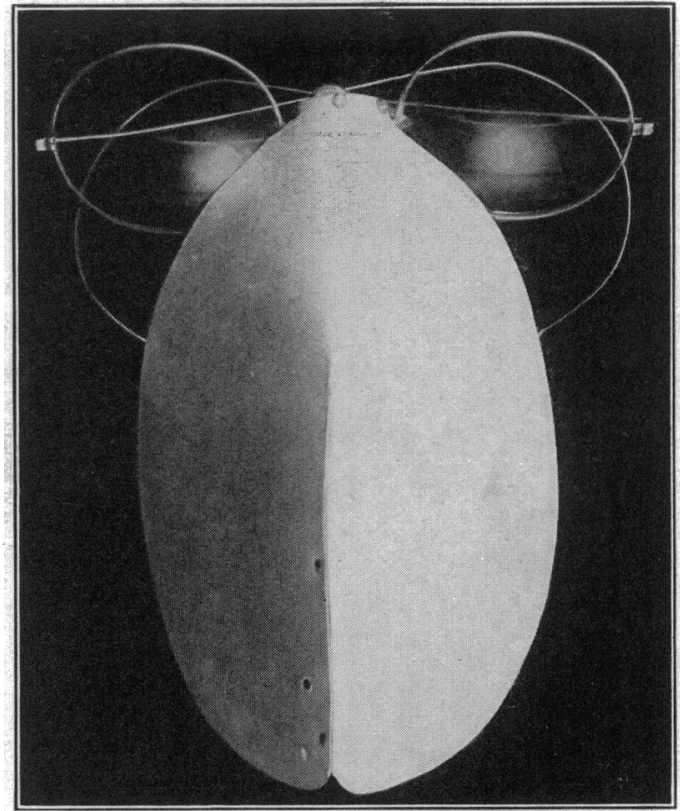

Device for protection against infection in nose and throat examinations.

with the ease with which it may be sterilized by boiling, would, I believe, make it popular with many.

513 North Charles Street.

\section{APPARATUS FOR INTRAVENOUS INJECTION OF NEO-} SALVARSAN IN CONCENTRATED SOLUTION

David Geiringer, M.D., New York

Instructor in Genito-Urinary Surgery and Syphilis, Post-Graduaie Medical School

This apparatus is recommended for the intravenous administration of neosalvarsan according to the method of Ravaut.

It consists of two 20 c.c. record syringes ( $A$ and $B$ ), two pieces of rubber tubing 3 inches long $(C, C)$, one piece of 
tubing 1 inch long $(E)$, a two-way valve $(D)$ and a coupling for the needle $(F)$.

The syringe $A$ is filled with normal saline. Syringe $B$ is filled with the neosalvarsan solution, which is prepared by dissolving $0.9 \mathrm{gm}$. in 20 c.c. of freshly distilled water at room temperature. If smaller doses are used, correspondingly less water is employed.

Syringe $B$ being filled with the neosalvarsan solution, it is connected with one inlet of the valve $D$ by means of the rubber tubing $C$. The air is expelled by advancing the piston into the barrel until some of the solution escapes from the outlet of the valve. The handle of the valve should be in position 2 .

Next, the handle of the valve is swung in position 1 . The syringe $A$ is filled with normal saline and connected with the valve $D$. The coupling and tubing are attached to the outlet of the valve. The air is expelled by injecting the saline into the tubing until it escapes from coupling $\boldsymbol{F}$.

The needle, having been inserted into the vein, is connected with the syringes by means of the coupling $F$. The normal saline is first injected to determine if the puncture has been properly made. Usually 2 or 3 c.c. suffice. If the saline flows satisfactorily, the handle of the valve is swung back to position 2; this opens the way for the neosalvarsan, which is then very slowly injected, consum.

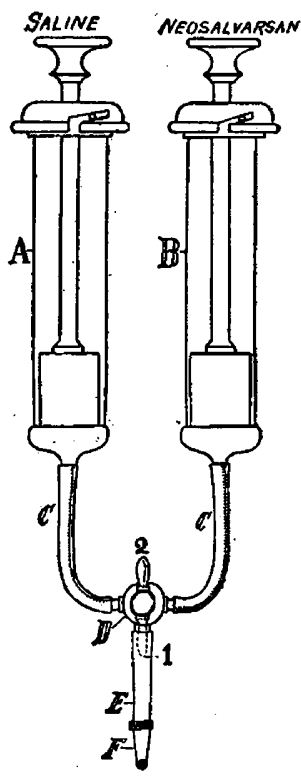

Convenient apparatus for the intravenous in. jection of neosalvarsan in concentrated solution. ing from about five to eight minutes.

The object in using the saline is to avoid injecting the neosalvarsan around the vein into the subcutaneous tissues, causing painful infiltrations which persist for a long time. Even in the hands of the most skilful, the needle sometimes pierces both walls of the vein or has not penetrated deeply enough, allowing the escape of the solution into the surrounding tissues.

This apparatus is a very simple one and can be assembled at home. The valve can be obtained from any instrument dealer, while a No. 12 soft-rubber catheter suffices for the tubing. It can be used with any needle.

1186 Madison Avenue.

\section{AN INEXPENSIVE SCREW-HOLDER FOR USE IN BONE-SURGERY}

Gilbert L. Bailey, M.D., OAk Park, Ill.

A simple and inexpensive device for holding a screw in applying Lane bone-plates or fixing detached fragments of

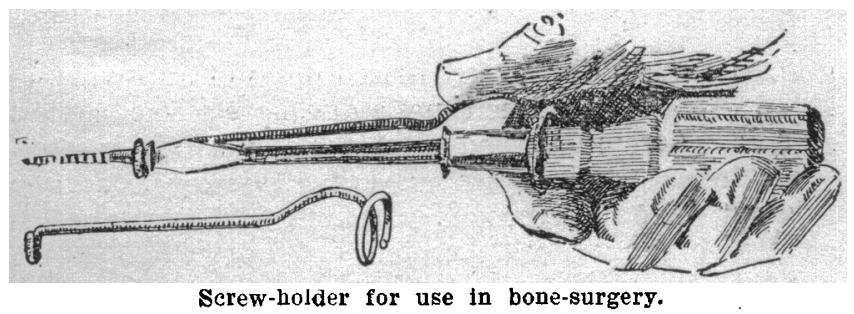

bone may be made of No. 13 copper-plated steel spring wire which can easily be bent and attached to an ordinary screwdriver, as shown in the illustration. The whole apparatus costs thirty cents and a little time, and $I$ have found it of service in many bone cases.

The wire clip holds the screw until it is well started in the desired direction in the drill-hole prepared for it and it is released by pressing the wire with the thumb at the handle.

\section{IMPROVED CUT-OFF: A MODIFICATION OF THE INSTRUMENT USED WITH THE VALENTINE} IRRIGATOR

\section{S. Brron Golosmith, B.S., M.D., Philadelphia}

The accompanying illustration is that of a device which $I$ have had constructed to facilitate urethral irrigations. It is a modification of the shut-off used with the Valentine irrigator. In irrigating the anterior urethra with the Valentine apparatus $I$ found it difficult to manipulate for the reason that two hands are required to stop the flow of fluid after each washing. My own instrument requires the use of only one hand as the fluid can be shut off or turned on by simply operating the handle (A).

Within the metal casing $(F)$ is a pressure-bar $(B)$ which compresses the rubber tubing $(G)$ by means of a strong steel spring $(D)$. To allow the fluid to flow the handle is pressed down, thereby taking pressure off the tubing. When the anterior urethra is

full, or when desired, the handle is released and the flow is shut off automatically.

A t h u mb-catch $(C)$ is attached to the handle which can be adjusted so that the pressure may be taken off the rubber $t \mathbf{u} b$ ing when the instrument is not in use. Before the irrigating can is filled the thumb-catch is released. $T h$ is $p e r$ mits the pressurebar to compress the rubber tubing so as to prevent escape of the fluid.

In irrigating the bladder a continuous stream may be obtained by simply pressing on the handle and adjust. ing the thumb-catch. 247 South Thirteenth Street.

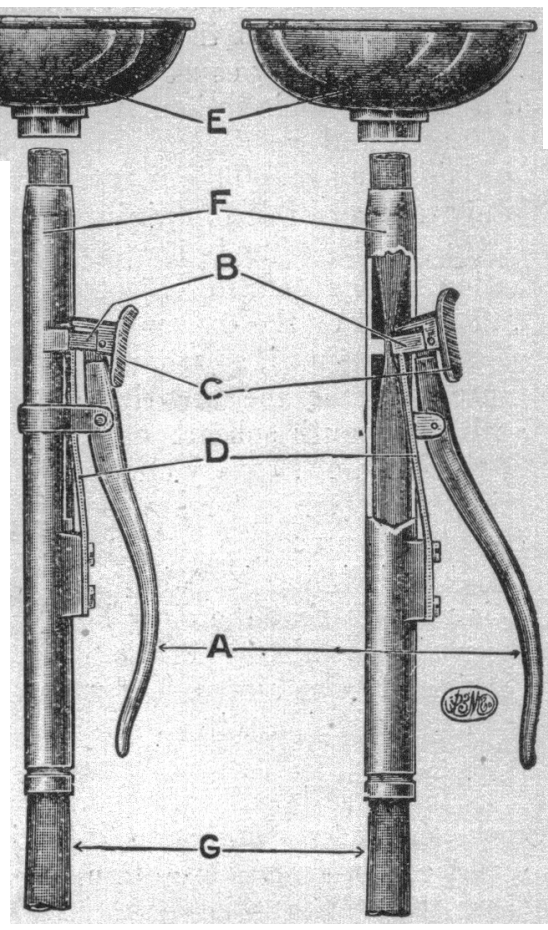

Improved cut-off; a modification of the instrument used with the Valentine irri-
gator; $A$, handle; $B$, pressure-bar; $O$, gator; $A$, handle ; $B$, pressure-Bar ; $O$,
thumb-catch $; D$, spring; $E$, shield ; $F$, casIng: $G$, rubber tube.

\section{SIMPLE ATTACHMENT FOR BLOOD-COUNTING PIPET}

\section{F. B. Schroeder, M.D., Princeton, ILL.}

This attachment consists of a small mirror mounted on a split metallic clamp or ring, the bore of which is slightly smaller than the diameter of the pipet. This will allow of free movement of the mirror, which is held in place by the spring action of the split ring.

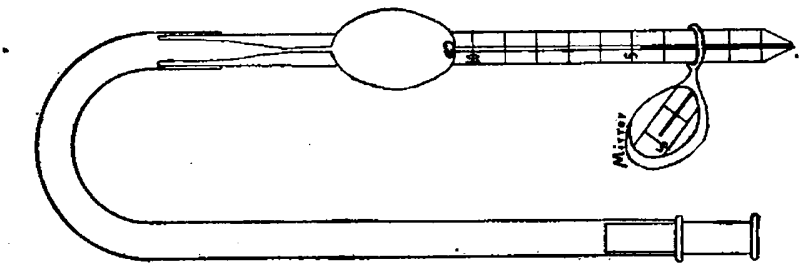

Mirror attached to blood-counting pipet.

By using this attachment the operator is enabled to observe the gradual ascent of the blood-column, and has no difficulty in obtaining the exact amount. 